\title{
Idiopathic copper-associated cirrhosis
}

INSERM

\section{Source}

INSERM. (1999). Orphanet: an online rare disease and orphan drug data base. Idiopathic copper-associated cirrhosis. ORPHA:209919

Idiopathic copper-associated cirrhosis is a rare copper-overload liver disease characterized by a rapidly prog ressive liver cirrhosis from the first few years of life leading to hepatic insufficiency and harboring a specific pathological aspect: pericellular fibrosis, inflammatory infiltration, hepatocyte necrosis, absence of steatosis, poor regeneration and histochemical copper staining. 